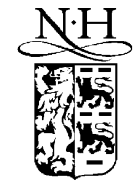

EISEVIER

\title{
Adsorption of asphaltenes from toluene on typical soils of Lublin region
}

\author{
Marta Szymula, Adam W. Marczewski* \\ Department of Radiochemistry and Colloid Chemistry, Faculty of Chemistry, Maria Curie-Sktodowska University, \\ M. Curie-Skłodowska Sq. 3, 20-031 Lublin, Poland
}

\begin{abstract}
Adsorption of asphaltenes on soils is one of the important problems, though largely underestimated, in environment protection of Lublin region. Asphaltene adsorption properties affect the way the contamination spreads in soil. Analysis of this phenomenon may help in localisation and elimination of oil spills. The asphaltenes studied were obtained from local drills (Świdnik near Lublin, Poland). In our previous paper, we investigated adsorption of asphaltenes from toluene on rock components (quartz, dolomite, calcite, kaolin as well as pure iron and titanium oxides). In order to simulate the natural oil spill conditions, we used toluene as solvent and typical soils from Lublin region as adsorbents (black earth, peat soil, lessive soil, brown soil, sandy podsolised soil, pararendzina soil). Main physicochemical properties of these soils were reported. Moreover, basic adsorption properties (nitrogen adsorption, adsorption of surfactants from water solutions, acidity, etc.) of several soil fraction were studied. We decided to use only certain mineral fractions with highest adsorption capacity, as other fractions have limited impact on total adsorption. Adsorption on soil fraction gives also some insight into relative importance of various soil components on summary soil properties. The results of adsorption measurements are described in terms of physical adsorption on heterogeneous solids.
\end{abstract}

(C) 2002 Published by Elsevier Science B.V.

PACS: 68.45.-v; 68.45.Da; 82.65.-i; 82.70.-y

Keywords: Asphaltenes; Asphaltene adsorption; Association; Ecology

\section{Introduction}

Studies of asphaltene/mineral interactions yield new results in the field of environmental chemistry. During the enhanced oil recovery (EOR) procedures insoluble asphaltene particles may appear in the environment. They may also originate from uncontrolled spill of oil products.

\footnotetext{
* Corresponding author. Tel.: +48-81-537-5624; fax: +48-81-533-2811.

E-mail address: adam.marczewski@umcs.lublin.pl (A.W. Marczewski).
}

It is well known that asphaltene interfacial activity is a consequence of the presence of functional groups in the molecule. Owing to various functional groups, i.e. carboxylic, hydroxyl, ether, ester, aldehyde, ketone, amine and amide, asphaltenes are able to create a surface charge at the interface [1-3]. Because of their interfacial activity, asphaltenes are of special interest from a colloidal point of view [4-27]. Asphaltenes can adsorb electrolyte ions from brine solution [28-30] and they may be adsorbed from organic solution on rock reservoir and soils [1,31-39]. One should expect, that these adsorption processes are further complicated by the behaviour of asphaltenes in organic 
solutions. The solvated asphaltene crystallites are the primary particles of a colloidal dispersed phase. These particles can associate and aggregate forming large particles dependent on temperature, pressure and concentration $[7,8,11,13,17-27,30,40-43]$. It is well known that asphaltenes are natural surfactants stabilising water/crude oil emulsion [13, 14,44-53]. Thus, their adsorption on charged mineral surfaces could be considered as adsorption of ionic surfactants. It is well known that the shape of isotherms describing surfactant adsorption process strongly depends on its critical hemimicelle concentration and critical micelle concentration (CMC) which mark the onsets of distinct isotherm regions [31,54-58]. However, phenomenon of adsorption of natural, not exactly defined surfactant adsorption on not well determined adsorbents - soilsfrom non-polar and weakly polar non-aqueous solutions is largely unexplored.

\section{Experimental}

\subsection{Materials}

The asphaltenes used in this study were from Świdnik (near Lublin, Poland) crude oil. The oil had viscosity of $14.3^{\circ} \mathrm{E}\left(106 \mathrm{~mm}^{2} \mathrm{~s}^{-1}, 96 \mathrm{cP}\right)$ and a density of $881 \mathrm{~kg} \mathrm{~m}^{-3}$ at $293 \mathrm{~K}$. The asphaltene content of the crude oil was about 2 wt.\%. The asphaltenes were obtained from the crude oil as follows: the crude oil was mixed with five volumes of $n$-pentane and centrifuged at $2400 \mathrm{rpm}$ for $10 \mathrm{~min}$ to precipitate the heaviest fraction. The precipitated fraction (hereafter called asphaltenes) was removed and the flocculant (n-pentane) was evaporated at $365 \mathrm{~K}$ in a rotary evaporation unit [4]. Elemental analyses of the asphaltenes by Perkin-Elmer CHN 2400 showed the following: $\mathrm{C} 87.75 \%, \mathrm{H} 8.39 \%, \mathrm{~N} 0.52 \%$. The contents of $\mathrm{Cl}^{-}$and $\mathrm{HCO}_{3}{ }^{-}$ions in Świdnik reservoir brine were 45.03 and $0.08 \mathrm{~g} \mathrm{dm}^{-3}$, respectively.

For the further experiments, the asphaltenes were homogenised in the agate mortar. Black earth, peat soil, lessive soil, brown soil, sandy podsolised soil, pararendzina soil being a typical Lublin region soils, were used as adsorbents. The soil samples were taken in October 1994 and 1996 [59-61]. The sampling spots were situated far from inhabited areas and any active agricultural or industrial objects. The selected soils had not been farmed for last 30 years or so and were scarcely overgrown with short plants. Before sampling, the soil surface was cleaned of the overgrown plant parts and larger organic pieces. The samples were stored in polyethylene bags [62]. After transferring to the laboratory, the samples were dried in a drier at $80^{\circ} \mathrm{C}$ and then screened on a $1 \mathrm{~mm}$ sieve to remove stones and larger organic fragments. Soils were treated as followed: the $10-15 \mathrm{~cm}$ soil layer was washed on a $0.25 \mathrm{~mm}$ sieves into a $1 \mathrm{dm}^{3}$ glass beaker. Then the beaker was filled up with water and the contents mixed. The separation of soils into size fractions was carried out according Kohn's sedimentation method [63]. Specific surface area of each soil fraction $S_{\mathrm{BET}}$ was determined by measurements of nitrogen adsorption (ASAP 2405 sorption analyzer, Micromeritics Corp., USA).

Granulometric composition and some physicochemical properties of the studied soils, their designations (codes used in the paper) and specific surface areas are presented in the Table 1. Organic solvents, p.a. quality $n$-pentane and toluene, were supplied by Merck (Darmstadt, Germany).

\subsection{Method}

Static adsorption experiments were carried out at constant mass ratio of soil to asphaltene solution (1:10 for soils of low specific surface area, 1:100 for soils of high specific surface area) and concentrations (initial concentrations within the range $10-30,000 \mathrm{ppm}$ ) were measured after $24 \mathrm{~h}$ equilibration at room temperature (293 K). The amount of adsorbed asphaltenes was calculated from mass balance after determining the equilibrium concentration by UV-VIS absorption technique (M42 spectrophotometer, Carl Zeiss, Germany). The asphaltene solutions were diluted with toluene to the desired absorbance value.

\section{Results and discussion}

In our previous paper [31] on adsorption of asphaltenes on mineral surfaces we measured the spectra of asphaltenes in toluene in the usual absorption linearity range i.e. absorption $<1.5$ and concentrations below $\sim 50 \mathrm{ppm}$. We noticed the gradual change of spectrum shape, i.e. for higher concentrations of asphaltene 
Table 1

Granulometric composition and some physicochemical properties of the soils

\begin{tabular}{|c|c|c|c|c|c|c|c|c|c|}
\hline Soil & Code & $\begin{array}{l}\text { Bulk density } \\
\left(\mathrm{g} \mathrm{cm}^{-3}\right)\end{array}$ & $\begin{array}{l}\text { Particle } \\
\text { size }(\mathrm{mm})\end{array}$ & $\begin{array}{l}\text { Mass } \\
\text { fraction, } X_{\mathrm{w}}\end{array}$ & $\begin{array}{l}S_{\mathrm{BET}} \\
\left(\mathrm{m}^{2} \mathrm{~g}^{-1}\right)\end{array}$ & $\begin{array}{l}\text { Fractional BET } \\
\text { surface area }\end{array}$ & $\begin{array}{l}\text { Pore volume, } \\
V_{\mathrm{p}}\left(\mathrm{cm}^{3} \mathrm{~g}^{-1}\right)\end{array}$ & $\begin{array}{l}\text { Micropore } \\
\text { volume }\left(\mathrm{cm}^{3} \mathrm{~g}^{-1}\right)\end{array}$ & $\begin{array}{l}\text { Mean pore } \\
\text { size }(\AA)\end{array}$ \\
\hline \multirow[t]{5}{*}{ Black earth soil } & G1 & 1.03 & & 1.0 & & & & & \\
\hline & $\mathrm{G} 1 \mathrm{f} 1^{\mathrm{a}}$ & & $0.5-0.2$ & 0.479 & 0.31 & 0.139 & 0.0003 & 0 & 50 \\
\hline & G1f2 & & $0.2-0.1$ & 0.375 & 1.7 & 0.596 & 0.0032 & 0 & 76 \\
\hline & G1f3 & & $0.02-0.01$ & 0.138 & 1.9 & 0.244 & 0.0042 & 0 & 89 \\
\hline & $\mathrm{G} 1 \mathrm{f} 4^{\mathrm{a}}$ & & $<0.002$ & 0.008 & 2.7 & 0.021 & 0.0070 & 0 & 103 \\
\hline \multirow[t]{4}{*}{ Peat soil } & G2 & 0.52 & & 1.0 & & & & & \\
\hline & G2f1 & & $0.2-0.1$ & 0.414 & 2.4 & 0.441 & 0.0022 & 0 & 38 \\
\hline & $\mathrm{G} 2 \mathrm{f} 2^{\mathrm{a}}$ & & $0.02-0.01$ & 0.017 & 2.1 & 0.015 & 0.0033 & 0 & 63 \\
\hline & $\mathrm{G} 2 \mathrm{f} 3$ & & $<0.002$ & 0.569 & 2.1 & 0.543 & 0.002 & 0 & 39 \\
\hline \multirow[t]{3}{*}{ Lessive soil } & G3 & 1.35 & & 1.0 & & & & & \\
\hline & G3f1 & & $0.2-0.1$ & 0.997 & 15.2 & 0.989 & 0.0198 & 0.00056 & 52 \\
\hline & $\mathrm{G} 3 \mathrm{f} 2^{\mathrm{a}}$ & & $<0.002$ & 0.003 & 54.6 & 0.011 & 0.0764 & 0.00226 & 56 \\
\hline \multirow[t]{4}{*}{ Brown soil } & G4 & 1.24 & & 1.0 & & & & & \\
\hline & G4f1 & & $0.2-0.1$ & 0.809 & 5.8 & 0.742 & 0.0108 & 0 & 75 \\
\hline & G4f2 & & $0.02-0.01$ & 0.183 & 7.4 & 0.214 & 0.0139 & 0 & 75 \\
\hline & $\mathrm{G} 4 \mathrm{f} 3^{\mathrm{a}}$ & & $<0.002$ & 0.008 & 33.5 & 0.044 & 0.0576 & 0 & 69 \\
\hline \multirow[t]{3}{*}{ Sandy podsolised soil ${ }^{\mathrm{a}}$} & $\mathrm{G} 5^{\mathrm{a}}$ & 1.86 & & 1.0 & & & & & \\
\hline & $\mathrm{G} 5 \mathrm{f} 1^{\mathrm{a}}$ & & $0.5-0.2$ & 0.995 & 0.49 & 0.909 & 0.0008 & 0 & 68 \\
\hline & $\mathrm{G} 5 \mathrm{f} 2^{\mathrm{a}}$ & & $0.005-0.002$ & 0.005 & 14.6 & 0.091 & 0.0378 & 0 & 104 \\
\hline \multirow[t]{6}{*}{ Pararendzina soil } & G6 & 1.17 & & 1.0 & & & & & \\
\hline & $\mathrm{G} 6 \mathrm{f} 1^{\mathrm{a}}$ & Sandy margle & $0.5-0.2$ & 0.264 & 0.58 & 0.002 & 0.001 & 0 & 100 \\
\hline & G6f2 & & $1.5-1.0$ & 0.283 & 111.0 & 0.4660 & 0.277 & 0.0024 & 72 \\
\hline & $\mathrm{G} 6 \mathrm{f} 3^{\mathrm{a}}$ & & $0.02-0.01$ & 0.094 & 50.0 & 0.0700 & 0.118 & 0.0013 & 94 \\
\hline & G6f4 & & $0.01-0.005$ & 0.113 & 50.1 & 0.084 & 0.118 & 0.0019 & 94 \\
\hline & G6f5 & & $<0.002$ & 0.246 & 103.8 & 0.377 & 0.237 & 0.0036 & 91 \\
\hline
\end{tabular}

\footnotetext{
a Soil samples not used in adsorption experiment.

${ }^{\mathrm{b}}$ Fractional BET surface area $X_{\mathrm{s}, i}$ is defined as a ratio of a given fraction's surface to the total sample BET surface area, $X_{\mathrm{s}, i}=S_{\mathrm{BET}, i} X_{\mathrm{w}, i} / \sum S_{\mathrm{BET}, j} X_{\mathrm{w}, j}$.
} 


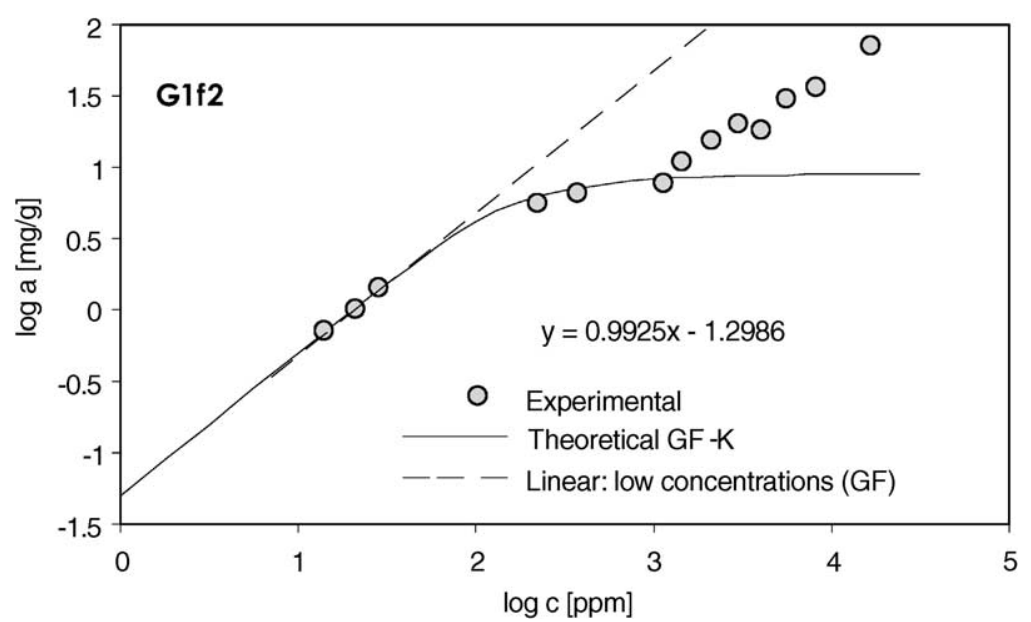

Fig. 1. Adsorption of asphaltenes on soil fraction G1f2 (Table 1) in log-log co-ordinates. Solid line represents theoretical GF-K isotherm with parameters obtained by numerical fitting (Table 2) to data with concentrations below $1500 \mathrm{ppm}$. Dashed line and linear equation $y(x)$ represent a linear section of GF-K isotherm for low concentrations of asphaltenes (GF, GF-K: minimization of $\log (a)$ error; see text and Appendix A).

solution (over $200 \mathrm{ppm}$ ) an additional absorption peak $(350-400 \mathrm{~nm})$ appears. This peak is connected with well-known phenomenon of asphaltene association in toluene solution (value of critical micellisation concentration for asphaltene in toluene solution is $\sim 3000 \mathrm{ppm})[7,8,21,42]$.

We also analysed the relationships between absorption versus concentration in $\log -\log$ co-ordinates for several spectrum wavelengths $\lambda: 240,270,290,300$, 350 and $400 \mathrm{~nm}$, as well as for the absorption peak maximum $(\sim 288 \mathrm{~nm})$. We found that the widest range of $\log -\log$ linearity is obtained for the peak maximum. We used this wavelength and the calibration in all the subsequent adsorption experiments.

The adsorption experiments were carried out for a wide range of initial concentrations and five typical Lublin's region soils. The exemplary isotherms presented in the Figs. 1-5 describe the adsorption processes of asphaltene on soils. Fig. 1 shows the adsorption on black earth soils (G1, size fraction f2:

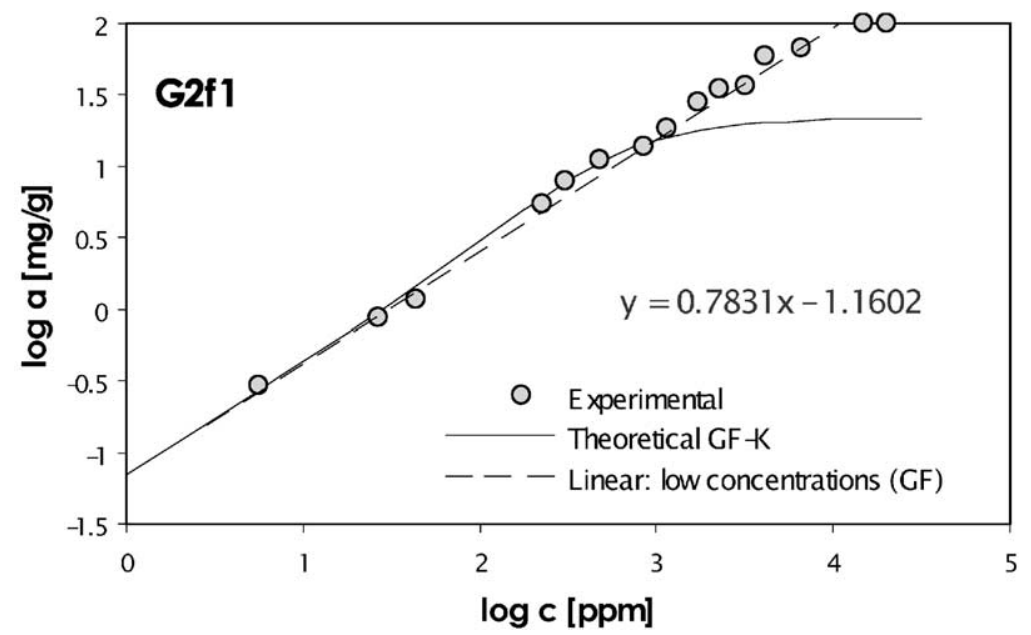

Fig. 2. Adsorption of asphaltenes on soil fraction G2f1 (Table 1) with GF-K isotherm fitted to data with concentrations below 1000 ppm (variables and pictograms are same as in Fig. 1). 


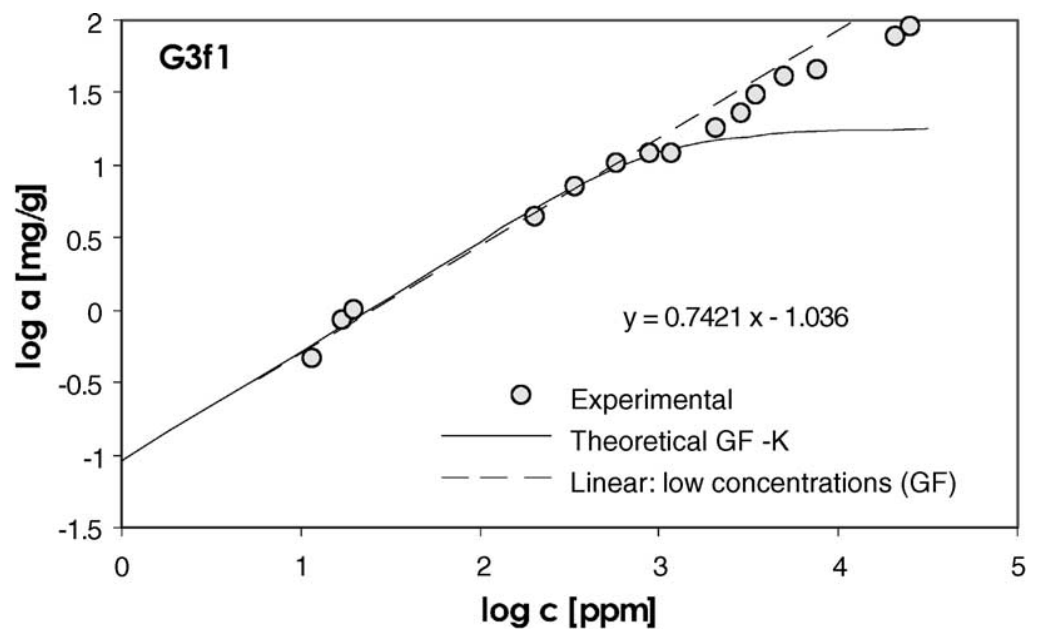

Fig. 3. Adsorption of asphaltenes on soil fraction G3f1 (Table 1) with GF-K isotherm fitted to data with concentrations below 1500 ppm (variables and pictograms are same as in Fig. 1).

$0.2-0.1 \mathrm{~nm})$. Fig. 2 shows the adsorption on peat soil (G2, size fraction f1: $0.2-0.1 \mathrm{~nm}$ ). Fig. 3 shows adsorption on lessive soil (G3, size fraction f1: 0.2$0.1 \mathrm{~nm}$ ). Figs. 4 and 5 show adsorption on brown soil (G4, size fraction $\mathrm{f} 1: 0.2-0.1 \mathrm{~nm}$ ) and pararendzina soil (G6, size fraction f5: $<0.002 \mathrm{~nm}$ ), respectively. Typically used plot of adsorption $(a)$ versus equilibrium concentration $(c)$ allows for easy analysis of isotherm course in the medium and high concentration range. However, the log-log plot we used, exposes lower concentrations and general adsorption trends over wide concentration range.

One can see that for the low concentration range adsorption can be successfully described by simple Freundlich (F) isotherms (straight line $\log a$ versus $\log c$ ). For higher concentrations we can see two types of isotherm behaviour. For G1, G2, G3 and G5 soils we observe small upward isotherm inflection $(\log c \sim 2-$ 2.5 ), which suggests the existence of some kind of lateral interactions. Taking into account the shape of

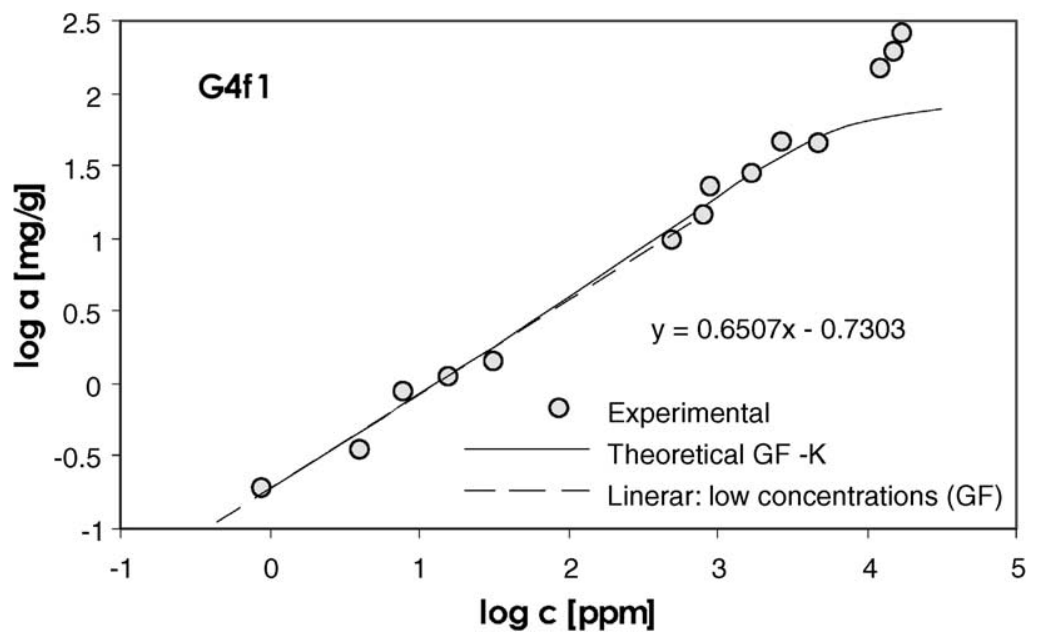

Fig. 4. Adsorption of asphaltenes on soil fraction G4f1 (Table 1) with GF-K isotherm fitted to data with concentrations below 5000 ppm (variables and pictograms are same as Fig. 1). 


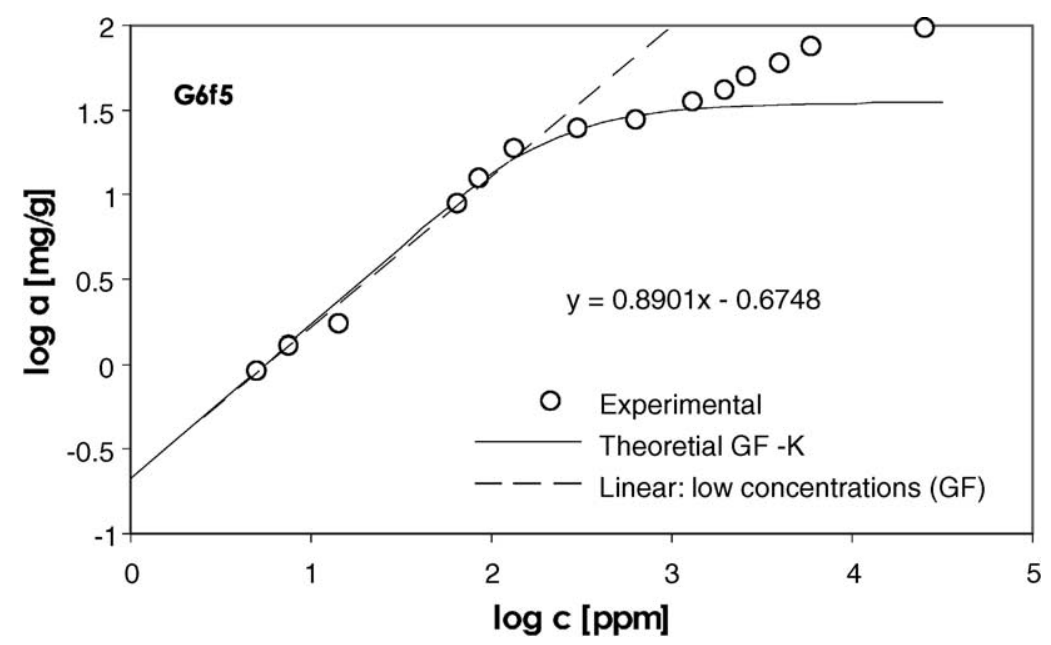

Fig. 5. Adsorption of asphaltenes on soil fraction G6f5 (Table 1) with GF-K isotherm fitted to data with concentrations below 3000 ppm (variables and pictograms are same as in Fig. 1).

isotherm together with our knowledge about the nature of micellisation processes we tried to fit the Generalised Freundlich (GF) isotherm (Freundlich-type heterogeneity in monolayer adsorption) combined with the simplified Kiselev model for adsorption of associating molecules [64], denoted here as Generalized Freundlich-Kiselev (GF-K) model.

$a=a_{m}\left(\frac{K c\left[1+K_{n}\left(a / a_{m}\right)\right]}{1+K c\left[1+K_{n}\left(a / a_{m}\right)\right]}\right)^{m}$ where $a$ is the adsorption value, $a_{m}$ the adsorption capacity, $c$ the concentration, $K$ the adsorption equilibrium constant, $m$ the heterogeneity coefficient and $K_{n}$ the Kiselev association constant. For small concentrations, this isotherm becomes identical with $\mathrm{GF}$ and $F$ equations.

The results of fitting are presented in Table 2 as well as solid lines in Figs. 1-3 and 5. One can see that such an explanation is quite reasonable. We should have in our mind that some optimisation parameters might not

Table 2

Correlation of best-fit parameters of GF-K isotherm (Eq. (A.1)) for adsorption of asphaltenes on soil fractions (Table 1) with soil properties

\begin{tabular}{lcllllll}
\hline $\begin{array}{l}\text { Soil fraction } \\
\text { code }\end{array}$ & $S_{\text {BET }}\left(\mathrm{m}^{2} \mathrm{~g}^{-1}\right)$ & $\begin{array}{l}V_{\text {meso }} \\
\left(\mathrm{cm}^{3} \mathrm{~g}^{-1}\right)\end{array}$ & $a_{m}\left(\mathrm{mg} \mathrm{g}^{-1}\right)$ & $m$ & $K\left(\mathrm{ppm}^{-1}\right)$ & $\begin{array}{c}K_{n} \\
\text { Best-fit } \\
\text { range }(\mathrm{ppm})\end{array}$ \\
\hline G1f2 & 1.7 & 0.0032 & 9 & 0.99 & $5.4 \times 10^{-3}$ & 1.2 & $<1500$ \\
G1f3 & 1.9 & 0.0042 & 20 & 0.80 & $1.1 \times 10^{-3}$ & 2.2 & $<1000$ \\
G2f1 & 2.4 & 0.0022 & 22 & 0.78 & $6.7 \times 10^{-4}$ & 2.4 & $<1000$ \\
G2f3 & 2.1 & 0.002 & 11 & 0.78 & $9.6 \times 10^{-4}$ & 2.4 & $<1000$ \\
G3f1 & 15 & 0.0198 & 18 & 0.74 & $8.2 \times 10^{-4}$ & 1.2 & $<1500$ \\
G4f1 $^{\text {c }}$ & 5.8 & 0.0108 & 85 & 0.65 & $8.3 \times 10^{-5}$ & 1.8 & $<5000$ \\
G4f2 & 7.4 & 0.0139 & 95 & 0.66 & $1.32 \times 10^{-4}$ & $0^{\mathrm{a}}$ & $<7000$ \\
G6f2 & 11 & 0.277 & 38 & 0.78 & $2.4 \times 10^{-3}$ & $0.2^{\mathrm{a}}$ & $<3000$ \\
G6f4 & 50 & 0.118 & 38 & 0.86 & $2.1 \times 10^{-3}$ & $4^{\mathrm{a}}$ & $<3000$ \\
G6f5 & 104 & 0.237 & 35 & 0.89 & $3.2 \times 10^{-3}$ & 1.5 & $<3000$ \\
Average & & & & 0.79 & $9.4 \times 10^{-4}$ & 1.7 &
\end{tabular}

${ }^{\text {a }}$ Unusually high or low value of $K_{n}$ may be attributed to high susceptibility of the fitting procedure to data scatter or missing first isotherm step.

${ }^{\mathrm{b}}$ In the case of equilibrium constant $(K)$ average of $\log K$ is calculated.

${ }^{\mathrm{c}}$ Brown soil fractions with parameters not correlated with other soils (Section 3). 


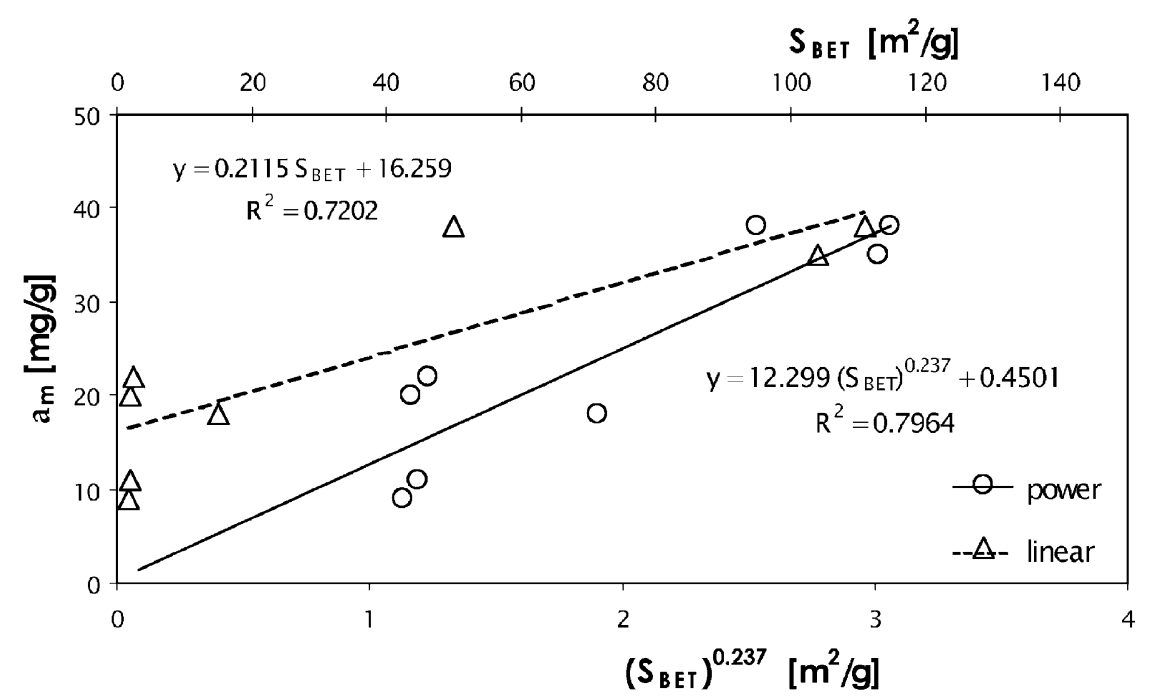

Fig. 6. Correlation of asphaltene adsorption capacity $a_{m}$ with BET surface area $S_{\mathrm{BET}}$ of soil fractions (brown soil G4 is not included).
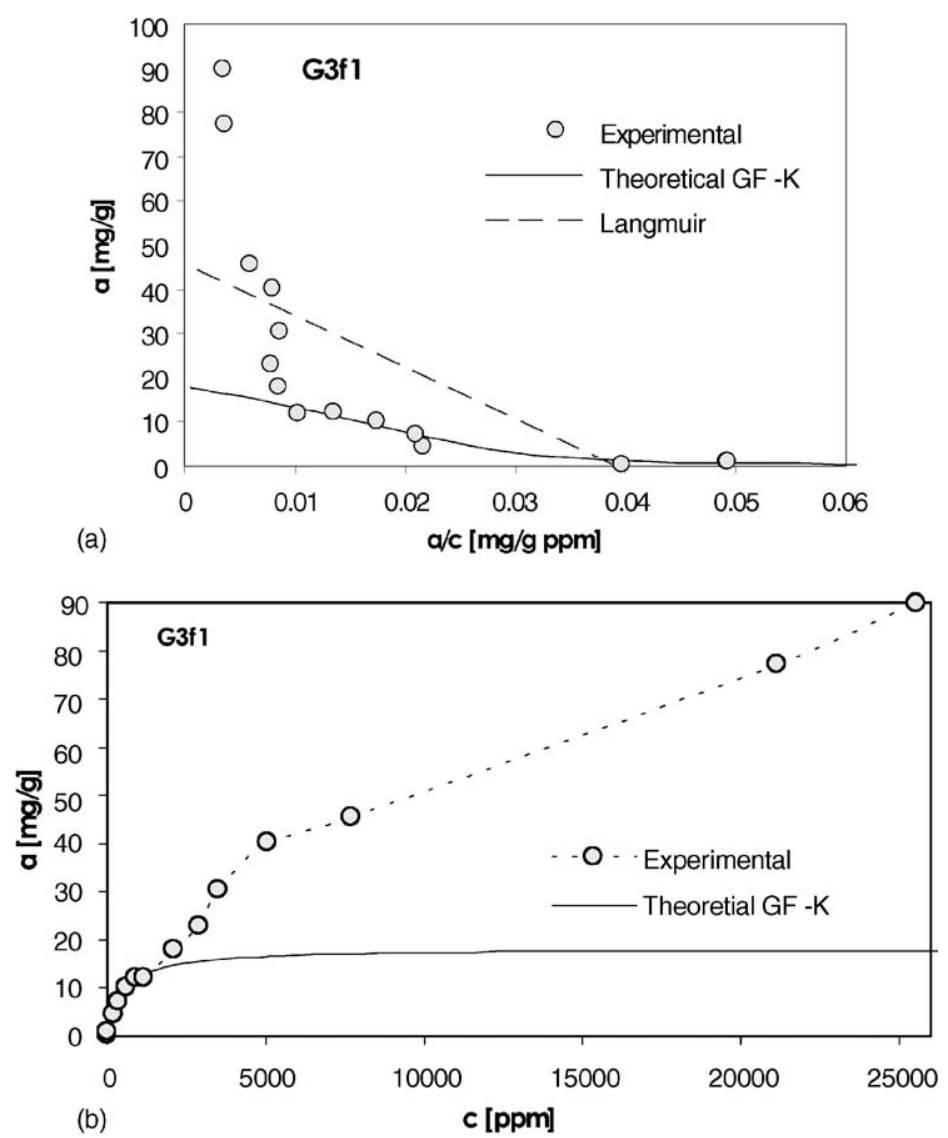

Fig. 7. Adsorption of asphaltenes on soil fraction G3f1 (Table 1). Solid line is calculated according to the GF-K equation with fitted parameters (Table 2 and Fig. 3). (a) Data shown in linear Langmuir co-ordinates ( $a$ vs. $a / c$ ). Dashed line is theoretical Langmuir plot for the best-fit parameters (minimized adsorption $a$ error). (b) Isotherm shown in typical adsorption vs. concentration co-ordinates. 
have physicochemically justified values, because the GF-K model does not take into account the multilayer formation and is an oversimplified of the true micellisation process. That was the reason we limited isotherm fitting to concentration below CMC, where both the phenomena are not strongly present. However, on the base of Fig. 4 and parameters in Table 2 one can see that the adsorption properties of brown soil are different than for other soils. Adsorption isotherms for G4-fractions in log-log co-ordinates have one long, almost linear, section over concentration up to $3000 \mathrm{ppm}$ which for higher concentration is followed by a clearly multilayer behaviour with increasing slope. No clear step close to the CMC $(1000-3000 \mathrm{ppm})$ is displayed in contrast to other soils (perhaps with some exception of soil G2, where this step is not very clear). In this case, it was difficult to distinguish the monolayer adsorption/association and multilayer/micellisation behaviours on the basis of isotherms alone. Lack of isotherm plateau below CMC may also result in larger optimisation error. Practically no correlation of asphaltene adsorption capacity $a_{m}\left(\mathrm{mg} \mathrm{g}^{-1}\right)$ with BET area $S_{\text {BET }}\left(\mathrm{m}^{2} \mathrm{~g}^{-1}\right)$ or mesopore volume $V_{\text {meso }}\left(\mathrm{cm}^{3} \mathrm{~g}^{-1}\right)$ is observed when all the systems are taken into account $\left(r^{2}=0\right.$ for all systems). However, after removing from considerations brown soil fractions G4f1 and G4f2, we have quite a good correlation, $r^{2}=0.72$, for both $a_{m}\left(S_{\mathrm{BET}}\right): \quad a_{m}=0.21 S_{\mathrm{BET}}+16.2$, and $a_{m}\left(V_{\text {meso }}\right)$ : $a_{m}=120 V_{\text {meso }}+13.9$ (Fig. 6). High surface areas
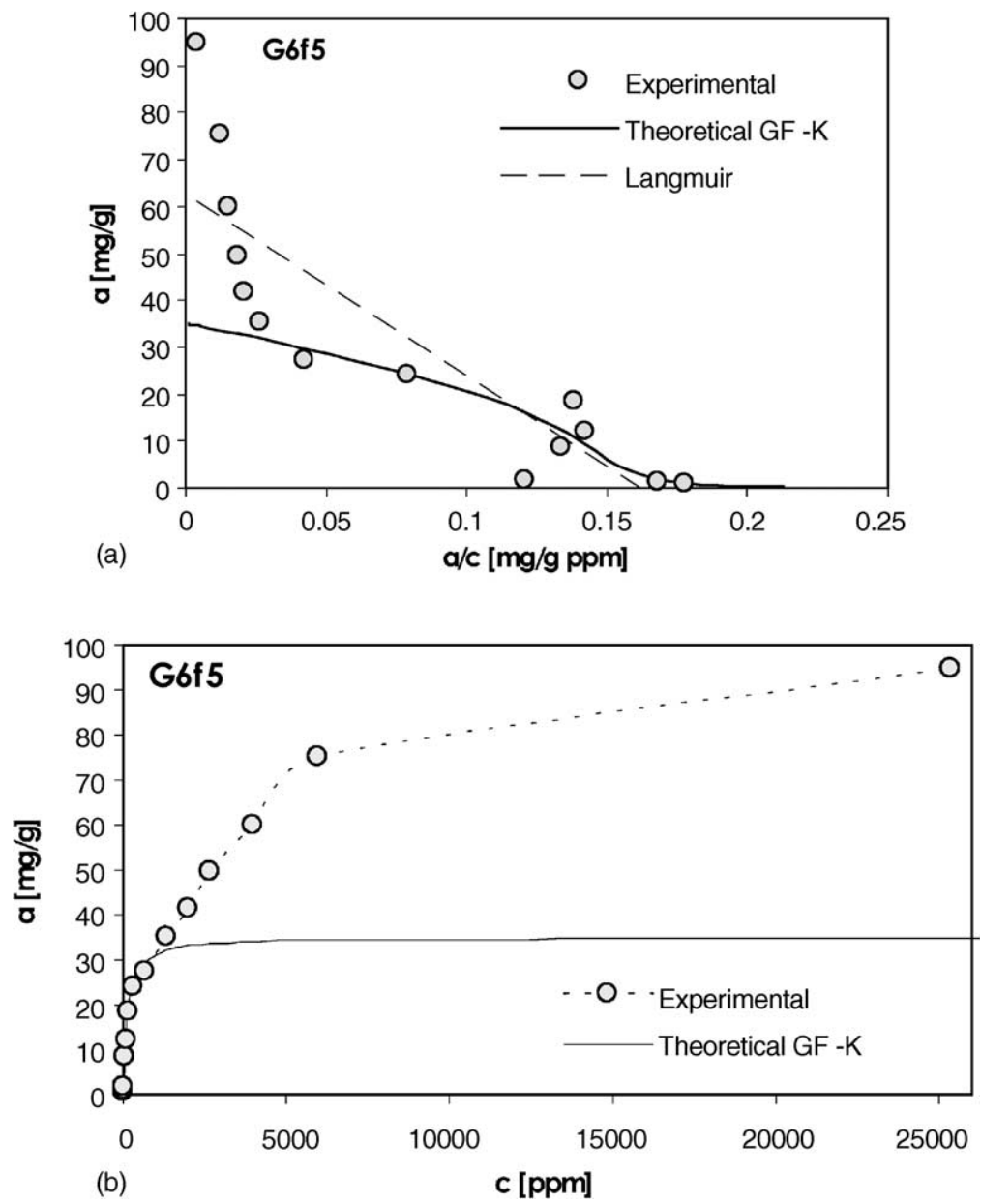

Fig. 8. Adsorption of asphaltenes on soil fraction G6f5 (Tables 1 and 2, Fig. 5) (pictograms and variables are same as in Fig. 7). 
usually come from both high pore volume with and small size of mesopores, however,, in this case only a weak correlation with the size of mesopores is observed. In our case, when the sizes of molecules used in BET measurement $\left(\mathrm{N}_{2}: M_{\mathrm{w}}=28 \mathrm{~mol} \mathrm{~g}^{-1}\right)$ and in solution (asphaltenes: $M_{\mathrm{w}} \sim 2000 \mathrm{~mol} \mathrm{~g}^{-1}$ ) are quite different, one should expect some kind of exclusion effect in smaller pores (usually also high $S_{\mathrm{BET}}$ areas). In fact, the best correlation is obtained with the power dependence of $a_{m}$ on $S_{\mathrm{BET}}: r^{2}=0.80$ for $a_{m}=12.3\left(S_{\mathrm{BET}}\right)^{0.237}+0.45$. Here, the value of a free term $a_{m}\left(S_{\mathrm{BET}}=0\right)=0.45$ is much smaller than for simple linear relations and-for similar soils-allows for simple prediction of probable adsorption capacity in asphaltene adsorption on the basis of soil properties (Fig. 6).

Very often adsorption of asphaltenes is described in terms of Langmuir isotherm [34,35,37], however our analysis shows that in most cases it is not possible [31]. For comparison we supply two Fig. 7 (G3f1) and Fig. 8 (G6f5). In Figs. 7a and 8a, the course of fitted Langmuir isotherm is compared with experimental data and GF-K fits in linear Langmuir co-ordinates ( $a$ versus $a / c)[65,66]$. This plot strongly emphasises all discrepancies from the model and often enables to see their source-be it multilayer formation, energetic heterogeneity or lateral interactions. One can see clearly that only short sections of data could be represented by Langmuir isotherm. In the case of GF-K isotherm it is clear why we limited our fit to low and moderate concentrations (below CMC). Steep section at low $(a / c)$ values reflects the build-up of multilayer/hemimicelles. In Figs. $7 b$ and $8 b$ compare theoretical (fitted) GF-K lines with experimental data (points) in traditional adsorption versus concentration plot. It is easy to understand why at first the Langmuir isotherm may be used in data fits (isotherm steps are not very much pronounced in this kind of plot).

\section{Conclusions}

Our adsorption measurements show that though very often adsorption of asphaltene on minerals is described as "Langmuir type" it is in fact quite distant from that simple model. All such adsorption isotherms contain initial lines of Freundlich characters with slope coefficients or/and inflections characteristic for lateral interactions, as well as multiple steps that may be related to surface phase reorientation, multilayer formation or hemimicelle formation. As the effect of these phenomena the character of soil surfaces may change from hydrophilic to hydrophobic.

\section{Appendix A.}

We decided to forgo a full optimisation, where all model parameters are optimised with a single criterion (e.g. least-squares fitting). Instead, we have applied a two-step method, which gives us much greater numerical stability and is less prone to wild parameter fluctuations.

\section{A.1. Two-step parameter fitting procedure}

(1) Fitting of linear section of GF-K (for low concentrations it becomes equivalent of Freundlich equation) - the values of $m$ and $\log \left(a_{m} K^{m}\right)$ are extracted:

$\log a=\log \left(a_{m} K^{m}\right)+m \log c$

(2) Data below the first step (i.e. monolayer region, below the CMC) is approximated with GF-K isotherm with values of $m$ and $\log \left(a_{m} K^{m}\right)$ taken from step 1 . The value of association constant $K_{n}$ and individual values of $a_{m}$ and $K$ are obtained by the minimisation of

$$
\text { S.D. }=\sqrt{\frac{\sum_{i=1}^{n}\left(\log a_{\mathrm{exp}, i}-\log a_{\mathrm{theor}}\left(c_{i}\right)\right)^{2}}{n-p}}
$$

where $n$ is the number of experimental points and $p=4$ is the number of fitted parameters.

Linear Langmuir $a$ versus $a / c$ plots (Figs. 7a and 8a) are used as a means of optimisation quality control.

\section{References}

[1] S. Kokal, T. Tang, L. Scharm, S. Sayegh, Colloids Surf. A: Physicochem. Eng. Asp. 94 (1995) 253.

[2] M. Salou, B. Siffert, A. Jada, Fuel 77 (1998) 343.

[3] M. Salou, B. Siffert, A. Jada, Fuel 77 (1998) 339.

[4] S.E. Friberg, H. Yang, Ø. Midttun, J. Sjöblom, P.A. Aikens, Colloids Surf. A: Physicochem. Eng. Asp. 136 (1998) 43.

[5] S.E. Taylor, Fuel 77 (1998) 821. 
[6] E.Y. Sheu, M.M. De Tar, D.A. Storm, in: M.K. Sharma, T.F. Yen (Eds.), Asphaltene Particles in Fossil Fuel Exploration, Recovery, Refining, and Production Processes, Proceedings of the International Symposium on Asphaltene Particles, in Fossil Fuel, Exploration, Recovery, Refining, and Production Processes, held in conjunction with the 24th Annual Meeting of the Fine Particle Society, Las Vegas, USA, 13-17 July 1992, Plenum Press, New York, p. 115.

[7] I.K. Yudin, G.L. Nikolaenko, E.E. Gorodetskii, E.L. Markhashov, D. Frot, Y. Briolant, V.A. Agayan, M.A. Anisimov, Petrol. Sci. Technol. 16 (1998) 395

[8] I.K. Yudin, G.L. Nikolaenko, E.E. Gorodetskii, E.L. Markhashov, V.A. Agayan, M.A. Anisimov, J.V. Sengers, Physica A 251 (1998) 253.

[9] L. Barré, D. Espinat, E. Rosenberg, M. Scarella, Revue de l'Institut Français du Pétrole 52 (1997) 161.

[10] S. Acevedo, G. Escobar, M.A. Ranaudo, J. Piñate, A. Amorín, Energy Fuels 11 (1997) 774

[11] J.S. Buckley, G.J. Hirasaki, Y. Liu, S. Von Drasek, J-X. Wang, B.S. Gill, Petrol. Sci. Technol. 16 (1998) 251.

[12] E.B. Sirota, Petrol. Sci. Technol. 16 (1998) 415.

[13] J.D. McLean, P.K. Kilpatrick, J. Colloid Interf. Sci. 196 (1997) 23.

[14] J.D. McLean, P.K. Kilpatrick, J. Colloid Interf. Sci. 189 (1997) 242.

[15] J.D. McLean, P.M. Spiecker, A.P. Sullivan, P.K. Kilpatrick, in: O.C. Mullins, E.Y. Sheu (Eds.), Structures and Dynamics of Asphaltene, Plenum Press, New York, 1998 (Chapter XII).

[16] S. Singh, J.D. McLean, P.K. Kilpatrick, J. Dispers. Sci. Technol. 20 (1999) 279.

[17] S.I. Anderson, J.G. Speight, J. Petrol. Sci. Eng. 22 (1999) 53.

[18] S.I. Anderson, S.D. Christiansen, Energy Fuels 14 (2000) 38.

[19] A.I. Victorov, N.A. Smirnova, Fluid Phase Equilib. 160 (1999) 471.

[20] J. Murgich, J.A. Abanero, O.P. Strausz, Energy Fuels 13 (1999) 378.

[21] R.M. Mohamad, A.C.S. Ramos, W. Loh, Energy Fuels 13 (1999) 323.

[22] W. Loh, R.S. Mohamed, A.C.S. Ramos, Petrol. Sci. Technol. 17 (1999) 147.

[23] E. Rogel, Energy Fuels 14 (2000) 566.

[24] O. Leon, E. Rogel, J. Espidal, G. Torres, Energy Fuels 14 (2000) 6.

[25] J.Z. Wu, J.M. Prausnitz, A. Firoozabadi, AIChE J. 46 (2000) 197.

[26] H.Q. Pan, A. Firoozabadi, AIChE J. 46 (2000) 416.

[27] H.Q. Pan, A. Firoozabadi, SPE Prod. Facil. 15 (2000) 58.

[28] J.S. Buckley, Energy Fuels 13 (1999) 328.

[29] J.D. McLean, P. Kilpatrick, Energy Fuel 11 (1997) 570.

[30] M. Szymula, W. Janusz, J. Jabloński, J. Dispers. Sci. Technol. 21 (2000) 785.

[31] A.W. Marczewski, M. Szymula, Colloids and Surfaces A. (2002), in press.

[32] S. Acevado, M.A. Ranaudo, G. Escobar, L. Gutierérrez, P. Ortega, Fuel 74 (1995) 595.
[33] G. Piro, L.B. Canonico, G. Galbariggi, L. Bertero, C. Carniani, SPE Prod. Facil. 11 (1996) 156.

[34] S. Acevedo, J. Castillo, A. Fernándéz, S. Goncalves, M.A. Ranaudo, Energy Fuels 12 (1998) 386.

[35] T. Pernyeszi, A. Patzko, O. Berkesi, I. Dekany, Colloids Surf. A: Physicochem. Eng. Asp. 137 (1998) 373.

[36] S. Standal, J. Haavik, A.M. Blokhus, A. Skauge, J. Petrol. Sci. Eng. 24 (1999) 131.

[37] S. Acevedo, M.A. Ranaudo, C. Garcia, J. Castillo, A. Fernándéz, M. Caetano, S. Gonzalez, Colloids Surf. A: Physicochem. Eng. Asp. 166 (2000) 145.

[38] L. Carbognani, Petrol. Sci. Technol. 18 (2000) 335.

[39] C.J. Daughney, Org. Geochem. 31 (2000) 147.

[40] D. Fenisten, L. Barré, D. Broseta, D. Espinat, A. Livet, J.N. Roux, M. Scarsella, Langmuir 14 (1998) 1013.

[41] D. Browarzik, H. Laux, I. Rahimian, Fluid Phase Equilib. 154 (1999) 285.

[42] M.A. Fahim, T.A.. Al-Sahhaf, A.S. Elkilani, Ind. Eng. Chem. Res. 40 (2001) 2748.

[43] T.G. Savvidis, D. Fenistein, L. Barré, E. Behar, AIChE J. 47 (2001) 206.

[44] R.S. Sandres, R.S. Chow, J.H. Masliyah, J. Colloid Interf. Sci. 174 (1995) 230.

[45] N.X. Yan, J.H. Masliyah, Colloids Surf. A: Physicochem. Eng. Asp. 11 (1996) 15.

[46] O. Urdahl, A.O. Fredheim, K.P. Løken, Colloids Surf. A: Physicochem. Eng. Asp. 123/124 (1997) 623.

[47] M.H. Ese, J. Sjöblom, H. Fordedal, O. Urdahl, H.P. Ronningsen, Colloids Surf. A: Physicochem. Eng. Asp. 123 (1997) 225.

[48] O. Mouraille, T. Skodvin, J. Sjöblom, J.L. Peytavy, J. Dispers. Sci. Technol. 19 (1998) 339.

[49] P.C. Schorling, D.G. Kessel, I. Rahimian, Colloids Surf. A: Physicochem. Eng. Asp. 152 (1999) 95.

[50] R.F. Lee, Spill Sci. Technol. Bull. 5 (1999) 117.

[51] M. Fingas, B. Fieldhouse, J. Mullin, Spill Sci. Technol. Bull. 5 (1999) 81.

[52] H. Laux, I. Rachimian, P.C. Schorling, Petrol. Sci. Technol. 17 (1999) 349.

[53] H.B. Fang, L. Zhang, L. Luo, S. Zhao, J.Y. An, Z.C. Xu, J.Y. Yu, A. Tien, H.T. Ottova, J. Colloid Interf. Sci. 238 (2001) 177.

[54] M. Colic, D.W. Fuerstenau, Langmuir 13 (1997) 6644.

[55] D.W. Fuerstenau, M. Colic, Colloid Surf. A: Physicochem. Eng. Asp. 146 (1999) 33.

[56] A. Fan, P. Somasundaran, N.J. Turro, Langmuir 13 (1997) 506.

[57] I.A. Polunina, A.A. Isirikyan, K.E. Polounine, S.S. Mikhailova, Colloids Surf. A: Physicochem. Eng. Asp. 160 (1999) 141.

[58] H.B. Fang, L. Zhang, L. Luo, S. Zhao, J.Y. An, Z.C. Xu, J.Y. Yu, A. Tien, H.T. Ottova, J. Colloid Interf. Sci. 238 (2001) 177.

[59] IAEA Measurement of Radionuclides in Food and the Environment, A Guidebook, Technical Reports, Series no. 295, IAEA, Vienna, 1989, p. 5.

[60] S. Chibowski, J. Zygmunt, Z. Klimowicz, Polish J. Environ. Stud. 6 (1997) 57. 
[61] S. Chibowski, J. Zygmunt, Z. Klimowicz, J. Radioanal. Nucl. Chem. 231 (1998) 57.

[62] S. Chibowski, J. Zygmunt, Z. Klimowicz, J. Radioanal. Nucl. Chem. 242 (1999) 278.

[63] B. Dobrzański, S. Uziak, Z. Klimowicz, J. Melke, Badanie gleb w laboratorium i w polu, UMCS, 1992.
[64] M. Jaroniec, R. Madey, Physical Adsorption on Heterogeneous Solids, Elsevier, Amsterdam, 1988.

[65] A.W. Marczewski, A. Deryło-Marczewska, M. Jaroniec, Chem. Scripta 28 (1988) 173.

[66] A. Derłyo-Marczewska, Langmuir 9 (1993) 23. 